our editorial on 'Current, new and emerging therapies for managing hyperglycaemia of type 2 diabetes'. ${ }^{1} \mathrm{He}$ has used the pages of the BJGP to promulgate a personal view against the tide of epidemiological and clinical trial evidence that glucose lowering has been shown to reduce microvascular events in type 2 diabetes. On the basis of the extensive evidence, consensus guidelines from national and international diabetes organisations (for example International Diabetes Foundation, American Diabetes Association, Diabetes UK, as well as NICE) have recommended the use of $\mathrm{HbA} 1 \mathrm{c}$ as a therapeutic target - which he omitted to address. The newer trials of ADVANCE and ACCORD were trials of 'how low should one go' in terms glycaemic targets as measured by $\mathrm{HbA1c}$. It is of interest that Dr Curtis fails to accept the results of the ADVANCE study where there were published treatment benefits on renal events.

The aim of our editorial was to summarise the differing drug classes available for the management of the hyperglycaemia and not to review major randomised outcome trials. There is now a wider drug choice which might allow tailoring of therapy to individuals many of whom are overweight or poor responders to current therapies. The progressive nature of type 2 diabetes, ignored by Dr Curtis, is a key therapeutic factor resulting in a need for combination of therapies and thus a potential role for newer therapies. Due to these reasons, plus the limited glucose lowering effects of all drug classes, therapeutic agents with different modes of action to enhance glucose lowering are often required. Current clinical practice often includes considering the use of alternative drug classes that do not affect weight, since this is one of the important adverse effects of subcutaneous insulins, as well as oral insulin secretagogues and thiazolidinediones.

We owe it to our patients to be aware of therapeutic advances and place them in the context of present therapies in order to improve glycaemia and reduce the burden of diabetes-related complications.

\section{Neil Munro}

Capelfield Surgery, Elm Road, Claygate, Esher, Surrey, KT10 OEH.

E-mail: neil.m.munro@btinternet.com

\section{Michael Feher}

Department of Clinical Pharmacology and

Therapeutics, Charing Cross and

Westminster Medical School,

Westminster Hospital, London, SW1 2AP.

\section{REFERENCE}

1. Curtis S. Managing hyperglycaemia. Br J Gen Pract 2008; 58(554): 728 .

DOI: 10.3399/bjgp08X342417

\section{Undergraduate education}

I was sorry to read the Back Pages article by a disappointed student who had met negativity about his choice of general practice as a career. ${ }^{1}$ I experienced the same in 1975 from a tutor in my second year ('GP? A bright girl like you? That's a real waste'.) Fortunately, it didn't put me off, and I can reassure all students that many of us have already taken action to ensure that the undergraduate programmes across the UK and Ireland now showcase general practice to advantage. There is evidence that increasing numbers of students are choosing general practice; for example, more than $20 \%$ making a firm choice $(F$ Lynch and A Howe, unpublished data 2008) compared to an inconstant $10 \%{ }^{2}$ in a study 7 years before. This reflects both high quality learning and interesting clinical experience in community-based placements. ${ }^{3}$ There is also extensive evidence that general practice is a challenging job (you won't be bored, Dan!) and has more academic opportunities than ever before, including more unanswered research questions than one life of academic endeavour could possibly cover.
It is human to talk up one's own preferences, but sadly students do still hear unfounded stereotyping and prejudice from members of one discipline about others. The RCGP, with its thriving Student Forum, its excellent new MRCGP curriculum, and its undisputed place at the table of the Academy of Royal Colleges, has led a shift of status for GP careers which is well deserved. This student has reminded us that there are still negative role models, but we can reassure him that many medical school and Deanery staff (as well as patients) now understand the value of GPs as clinicians, teachers, and researchers. Look at the work GPs do, not what is said about it - actions speak louder than words.

\section{Amanda Howe}

Professor of Primary Care, University of East Anglia, School of Medicine, Health Policy and Practice, University of East Anglia, Norwich, Norfolk, NR4 7TJ.

E-mail: amanda.howe@uea.ac.uk

\section{REFERENCES}

1. Furmedge D. GP stigma at medical school and beyond - do we need to take action? Br J Gen Pract 2008; 58(553): 581.

2. Howe A, Ives G. Does community-based experience alter career preference? New evidence from a prospective longitudinal cohort study of undergraduate medical students. Med Edu 2001; 35(4): 391-397.

3. Howe A. Patient-centred medicine through studentcentred teaching — a student perspective on the key impacts of community-based learning in undergraduate medical education. Med Edu 2001; 35(7): 666-672.

DOI: 10.3399/bjgp08X342426

\section{Community hospitals}

As a GP trainee, I have worked in district, general, and teaching hospitals alone. However, I recently received the opportunity to do an 8-month rotation in elderly stroke care and orthopaedic rehabilitation at Woking Community Hospital.

Woking Community Hospital provides NHS Walk-in centre and emergency 
dental access clinics. It has 48 beds for older people; 12 beds for younger physically-disabled people, and 20 beds for older patients with dementia.

Outpatient services including physiotherapy, podiatry, X-ray, community dentistry, family planning, paediatric, and geriatric clinics are available.

Geriatric in-patients generally include individuals from local acute hospitals requiring continued medical care and physiotherapy. However, we also manage complex community-based patients referred by local GPs, most of whom need further investigation and treatment. The type of GP referral, highlighted to me some of obstacles a GP may encounter in the community, such as a lack of immediate investigative facilities and specialist review. It encouraged me to re-evaluate the potential role of the proposed 'polyclinic' within primary care.

Lord Darzi has envisaged the replacement of single-manned GP surgeries with 'polyclinics' by 2009. 'Polyclinics' are planned to provide specialist services run by several health professionals based in a single location. However, the Sheffield Faculty of the RCGP recently debated Lord Darzi's review of the NHS. They concluded that general practice should continue to be locally accessible, personal, and the source of a wide range of services to provide effective continuity of care. ${ }^{1}$

It appears that perhaps the government should invest more into existing community hospitals, which to some extent already provide specialist inpatient and outpatient services. These hospitals could work alongside GPs without disrupting their existing setup, thus allowing GPs to nurture personal and trusting relationships with their patients', which to me, is a fundamental aspect of being a GP!

\section{Shaista Sultan}

Surrey. E-mail: shaiss/@aol.com

\section{REFERENCE}

1. Sheffield says no to polyclinics. RCGP News 2008; June: 1.

DOI: 10.3399/bjgp08X342435

\section{APMS contracts}

I read Dr Conlon's letter in your September edition ${ }^{1}$ with some incredulity and a great feeling of sympathy for those of his employees who may have been faced with redundancy or a loss of earnings in order for the practice to avoid a financial disaster. This was, after all, an APMS contract for which he made a successful bid at a price he felt was appropriate for the services he was offering. It is absolutely vital for any practice or consortium to formulate a sound business plan in advance of any APMS contract bid in order to see if it is economically viable. In this case, it clearly was not. Full credit must go to the PCT, of whom I am not acknowledged to be a great admirer, for increasing the payments by $85 \%$ when there was no contractual obligation for them to do so.

I hope that this example serves as an object lesson to all those practices who may be tempted to make bids for APMS contracts without doing the most basic arithmetic. It is unfortunate that more GPs today have not had the benefit of a grounding in the Classics. If they had, they would understand the meaning of the Latin expression caveat emptor.

\section{Charles Zuckerman}

Northfield Health Centre, 15 St Heliers Rd, Birmingham, B31 1QT.

E-mail: charles.zuckerman@blmc.co.uk

\section{REFERENCE}

1. Conlon M. The NHS at 60. Br J Gen Pract 2008; 58(554): 648 .

DOI: 10.3399/bjgp08X342444 